\title{
Effects of bioturbation in oxic and hypoxic conditions: a microcosm experiment with a North Sea sediment community
}

\author{
Stefan Forster ${ }^{1}$, Gerhard Graf ${ }^{2}$, Jarmila Kitlar ${ }^{2}$, Martin Powilleit $^{3}$ \\ ${ }^{1}$ Max Planck Institut für Marine Mikrobiologie, Fahrenheitstrasse 1, D-28359 Bremen, Germany \\ ${ }^{2}$ Geomar Forschungszentrum, Wischhofstrasse 1-4, D-23148 Kiel, Germany \\ ${ }^{3}$ Institut für Ostseeforschung, Seestrasse 15, D-18119 Rostock/Warnemünde, Germany
}

\begin{abstract}
Sediment cores of $20 \mathrm{~cm}$ diameter containing the natural benthic fauna were subjected to low oxygen conditions in a laboratory microcosm system. After several days of oxic conditions ('oxic stage') the oxygen content of the water was reduced to $25 \%$ saturation for $15 \mathrm{~d}$ ('hypoxic stage'), followed by a 'reoxygenation stage'. Effective solute transport rates were calculated using measurements with the conservative tracer ion bromide. Profiles of oxygen and $\Sigma \mathrm{CO}_{2}$ were measured and molecular diffusive as well as effective fluxes, accounting for effective solute exchange, were calculated. The overall response of the benthic community was to compensate for low oxygen content of the overlying water by increased pumping activity. On average, effective diffusion coefficients $\left(D_{\text {eff }}\right)$ were 3 times higher in hypoxia than under oxic conditions. $D_{\text {eff }}$ reached $1.5 \times 10^{-4} \mathrm{~cm}^{2} \mathrm{~s}^{-1}$, a value 30 times that of molecular diffusion. During hypoxia we observed low molecular diffusive $\mathrm{O}_{2}$ flux, higher effective $\mathrm{O}_{2}$ flux, as well as an increase in $\Sigma \mathrm{CO}_{2}$ within the sediment. We interpret this as a shift of transport away from diffusion within the bulk sediment interstices (oxic conditions) to the advective transport pathways along burrows during hypoxia. This facilitates fast transport of oxygen and bromide along burrows and contrasts with the slower transport of $\mathrm{CO}_{2}$ from the interstices governed by molecular diffusion. In this transient situation calulations based on gradients result in an unrealistic molar ratio of fluxes $\left(\mathrm{CO}_{2} / \mathrm{O}_{2}\right)$ as high as 11 .
\end{abstract}

KEY WORDS: Hypoxia · Oxygen · Transport · Bioturbation · North Sea

\section{INTRODUCTION}

From 1981 to 1983, prolonged, large-scale oxygen depletions occurred throughout the German Bight in the North Sea. In some areas oxygen concentration was below $60 \mu \mathrm{mol} \mathrm{l}^{-1}\left(\sim 2 \mathrm{mg} \mathrm{l}^{-1}\right)$. While mass mortality of certain benthic macrofauna was observed (Detlefsen \& Westernhagen 1983, Hickel et al. 1989), little is known about the response of infauna, especially whether they change their behaviour in regard to bioturbation. The purpose of the present study was to assess the effects of oxygen deficiency on a benthic community by measuring solute transport rates and related fluxes between the sediment and the water.

Benthic invertebrates that experience low oxygen concentrations may show different responses depending on their physiological abilities and survival strate- gies. Some bivalves are specifically tolerant, displaying regulative capacities to oxygen contents of less than $10 \%$ saturation (Dries 1975) at low oxygen utilisation rates. Among polychaetes both the regulation of oxygen concentration levels by increased ventilation of burrows with oxygenated water and the strategy by which physiological expenses are reduced have been described (Schöttler \& Grieshaber 1988, FeldsgaardPedersen 1991). Echinoderms are reported to be generally sensitive to low oxygen levels (Harper et al. 1981, Gaston 1985). Among crustaceans the thalassinid decapod shrimps are exceptionally well adapted to low oxygen tensions (Thompson \& Pritchard 1969, Pamatmat 1978, Zebe 1982).

Behavioural changes triggered by low oxygen concentrations, or increasing hydrogen sulfide levels (Theede et al. 1969), may be found in those species 
regulating $\mathrm{O}_{2}$ consumption. For example, Rosenberg et al. (1991) showed that the brittlestar Amphiura filiformis, which usually lives below the sediment-water interface, moves to the sediment surface in response to low oxygen concentrations. Another species, Ophiura albida, seems to reach out for more oxygen by standing up on its arm tips (Baden et al. 1990).

Meiofauna organisms also show migration in response to low oxygen levels and/or increased $\mathrm{H}_{2} \mathrm{~S}$ levels (Hendelberg \& Jensen 1993). Even though they are small they are able to mix the pore water, as has been demonstrated recently by Aller \& Aller (1992).

Relatively little is known about effects of behavioural change during hypoxia on solute transport in the sediment. We may expect that species dwelling within the sediment increase particle displacement and force a concomitant pore water flow in the interstices when trying to escape from the sediment. Increased irrigation by macrofauna living in tubes and burrows may also increase solute exchange.

In addition there will be physiological changes during hypoxia. Depending on the availability of oxygen, amongst other factors, the degradation of organic matter may be complete or result in some organic end products. Accordingly, the increasing flux of $\mathrm{CO}_{2}$ from the sediment during hypoxic conditions has been interpreted as a result of changes in anaerobic and aerobic metabolic processes occurring within the sediment community (Hargrave \& Phillips 1981, Andersen et al. 1986, Balzer 1989). We thus measured the magnitude of the changing molar $\mathrm{CO}_{2} / \mathrm{O}_{2}$ flux ratio in our experiment.

We experimentally simulated oxygen depletion to the level of 25 to $30 \%$ saturation ( 60 to $90 \mu \mathrm{mol} \mathrm{l}^{-1}$ ) using sediments from the southern German Bight. At this level of depletion changes in the organisms' behaviour may be anticipated.

\section{METHODS}

Sediment cores of $20 \mathrm{~cm}$ inner diameter were obtained on 22 October 1989 (RV 'Poseidon', cruise 164/2) with an USNEL box corer modified to carry 4 plexiglass core liners to the sea floor. A modified multiple corer (Barnett et al. 1984) was used to sample cores of $10 \mathrm{~cm}$ inner diameter. The sediment at $54^{\circ} 01^{\prime} \mathrm{N}, 07^{\circ} 49^{\prime} \mathrm{E}$ at $35 \mathrm{~m}$ water depth consists of silty sand with $52 \%$ weight of particles in the 125 to $250 \mu \mathrm{m}$ fraction. Cores were transported and kept in the laboratory at in situ temperatures $\left(14^{\circ} \mathrm{C}\right)$ and in the dark within large cooling tanks. Water for a recycling seawater system was pumped from $2 \mathrm{~m}$ above the sea bed with an impeller pump.

Oxygen profile measurements and pore water extraction for $\Sigma \mathrm{CO}_{2}$ and bromide tracer profiles were ob- tained from the same $20 \mathrm{~cm}$ core during a single sampling, with 1 exception. Measurements of oxygen for the oxic stage (see below) were performed on samples obtained in June 1989 (temperature $9^{\circ} \mathrm{C}$ ). $\Sigma \mathrm{CO}_{2}$ and bromide transport measurements for the oxic stage were performed on samples taken in August 1989 (temperature $16^{\circ} \mathrm{C}$ ). Even though there was a temperature increase of $6^{\circ} \mathrm{C}$ from May to October, constant solute tracer transport (Kitlar 1991), almost identical $\Sigma \mathrm{CO}_{2}$ profiles (Powilleit 1991) and a stable position of the redox discontinuity layer (Forster 1991) indicated no major shift in the sediment system. Hence, we considered conditions found in May and August to be sufficiently similar to those in October for the following comparison of experimental stages to be meaningful.

Molecular diffusion experiments using $\mathrm{Br}^{-}$tracer were conducted in $10 \mathrm{~cm}$ cores. A total of 18 sediment cores were each covered with a lid and connected to 2 seawater reservoirs of $200 \mathrm{l}$ each. Water circulated from the reservoir through the lid to each core and back. Inflowing water was introduced into each core horizontally $5 \mathrm{~cm}$ above the sediment-water interface. Effluent water left the cores immediately below the lids, thus ensuring complete renewal of the water column in a core from below. Sensors made it possible to continuously control the temperature in the aquaria, the $\mathrm{O}_{2}$ concentration in the reservoirs and in 4 selected sediment cores. In this recycling seawater system turnover time was between 0.5 and $1.5 \mathrm{~h}$.

Fauna found in this sediment belonged to the Nucula nitidosa community with a biomass of approximately $7 \mathrm{~g}$ ash-free dry wt $\mathrm{m}^{-2}$ (Salzwedel et al. 1985, Hickel et al. 1989). Density varied between 1402 and 2117 ind. $\mathrm{m}^{-2}$ (own data not shown). Specifically, the dominant macroinvertebrates in the sediment cores used here were the echinoderms Ophiura albida, Amphiura filiformis and Echinocardium cordatum, the decapod Callianassa subterranea, the polychaetes Lanice conchilega and Nephtys hombergii, and the bivalve Nucula nitida (Kitlar 1991).

Time course of experiments. The experiment consisted of 3 consecutive stages: oxic, hypoxic and reoxygenation (Fig. 1). The cores were left unstoppered for $6 \mathrm{~d}$ and the water column aerated in order to mimic conditions found at the station in October 1989 (33\% salinity, $13.6^{\circ} \mathrm{C}, 87 \% \mathrm{O}_{2}$ saturation; $100 \%$ saturation $=$ $266 \mu \mathrm{mol} \mathrm{l^{-1 }}$ ). Then the flow-through system was installed by stoppering the cores. The water reservoirs were continuously bubbled with air for $2 \mathrm{~d}$ (oxic stage). From Day 9 on, nitrogen was bubbled in the reservoirs causing the $\mathrm{O}_{2}$ concentration to fall below $20 \%$ saturation within $2 \mathrm{~h}$. In the cores it took 4 to $7 \mathrm{~h}$ for this decrease to take place. A period of $15 \mathrm{~d}$ followed when the concentration of $\mathrm{O}_{2}$ remained between 20 and $30 \%$ saturation (hypoxic stage). On Day 24 air was again 


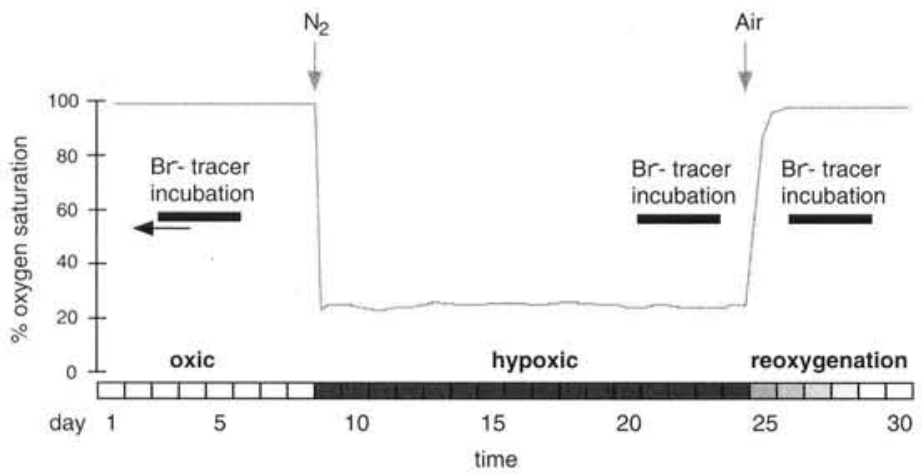

Fig. 1. Scheme of experimental variation in oxygen saturation level during the incubation of sediment cores. Sediment cores experienced the same oxygen saturation changes during the course of the experiment until they were incubated with bromide tracer and subsequently sliced. For each of the 3 experimental stages, 3 previously frozen cores (10 cm diameter) were incubated with tracer as zero controls and 3 sediment cores ( $20 \mathrm{~cm}$ diameter) with live macrofauna, which increase solute transport, were incubated for $3 \mathrm{~d}$ each. At the end of each tracer incubation, oxygen microprofiles were measured in 1 core, which was subsequently sampled for $\Sigma \mathrm{CO}_{2}$ and water content determinations. Data for the oxic stage are from measurements performed previous to the incubation period shown in this diagram (indicated by arrow; see text for details)

pumped into the reservoirs, raising $\mathrm{O}_{2}$ concentration in the core water to above $80 \%$ within $12 \mathrm{~h}$ (reoxygenation stage). Cores were disconnected from the flowthrough system only for the application of tracer or the final sectioning.

Solute exchange rates. Solute exchange rates were derived from experiments with the inert tracer ion $\mathrm{Br}^{-}$. To start an incubation $\mathrm{NaBr}$ was mixed into the supernatant water of each core and into the water reservoir to a final concentration of about $1.5 \mathrm{mg} \mathrm{NaBr} \mathrm{cm}^{-3}$, equivalent to $14.6 \mathrm{mmol} \mathrm{dm}^{-3}$. In each experiment three $20 \mathrm{~cm}$ cores containing the natural fauna and three $10 \mathrm{~cm}$ cores with macrofauna previously killed by deep-freezing were used to determine the bromide penetration enhanced by macrofauna and bromide transport by molecular diffusion, respectively. After $3 \mathrm{~d}$ incubation, cores were sliced in $0.5,1.0$ and $2.0 \mathrm{~cm}$ intervals, each slice mixed thoroughly, and $10 \mathrm{~cm}^{3}$ used for centrifugation at $4000 \mathrm{rpm}(4200 \times g)$ for $10 \mathrm{~min}$ with sediment samples held on a filter above a porous lid below which the pore water gathered. Pore water samples were obtained for determination of total dissolved carbonate (see below) and bromide. Water content was measured as weight loss after drying a preweighed volume of sediment at $60^{\circ} \mathrm{C}$. The remaining sediment from the cores was sieved for macrofauna.

Bromide concentrations were analysed by titration following the procedure of Kremling (1983; analytical error between \pm 1 and $\pm 8 \%$ over the range of concentrations used).
The hypoxic incubation of 6 cores with $\mathrm{Br}^{-}$ tracer lasted from Day 20 to Day 23. Solute tracer experiments during the reoxygenation stage ran from Day 25 through Day 28.

Bromide fluxes were modeled with a nonsteady-state 1-dimensional diffusion model supplied by W. Koeve (SFB 313, Kiel, Germany). Data for initial bromide concentration in the overlying water and water content of the sediment are used as initial input to the model. Transport between adjacent sediment layers follows Fick's First Law of Diffusion. Starting with bromide in the supernatant water only at time $=0$ the development of a tracer profile is simulated by iterating at time steps of $1 \mathrm{~h}$. Enhanced transport is modeled by changing the effective transport coefficient, $D_{\text {eff, }}$ for any sediment interval. In consecutive simulation runs the simulated bromide profile is fitted to the measured bromide-concentration profile by changing the magnitude of the diffusion coefficient at different sediment depths in order to achieve the lowest least-squared error over the entire sediment column analysed. The flux of bromide in excess of molecular diffusion can be expressed as a ratio $K_{\mathrm{BIO}}=D_{\text {eff }} / D_{\mathrm{s}}$ depicting the ratio of solute transport by macrofauna relative to that by molecular diffusion. Excess flux of bromide across the sediment-water interface is specifically given by $K_{\mathrm{BIO}}$ int, the bioturbation coefficient at the interface.

Simulation of tracer profiles in previously frozen cores can be obtained with a diffusion coefficient constant with depth. Simulation of profiles from live cores make it necessary to use a coefficient that varies with depth (Dicke 1986).

Determination of dissolved $\Sigma \mathrm{CO}_{2}$. Determination of dissolved $\Sigma \mathrm{CO}_{2}$ was conducted using a non-dispersive infrared (IR) analyser (Beckmann Ind. Model 880). We used a setup which is described by Altenbach (1987) for carbon content measurements in foraminifera. A closed, circulating airstream was continuously pumped through the IR analyser. Prior to each measurement all carbon dioxide and all water inside the system was removed by the absorbents ascarite and $\mathrm{Mg}(\mathrm{ClO})_{2}$. After injection of the filtered $1 \mathrm{~cm}^{3}$ sample and subsequent dropwise addition of $30 \%$ phosphoric acid $(\sim 0.5 \mathrm{ml})$ the released $\mathrm{CO}_{2}$ (enforced by flushing the sample with circulating gas) was measured for 5 to 8 min during which the carbon dioxide was evenly mixed within the circulating gas. The measured $\mathrm{CO}_{2}$ concentrations were integrated over a maximum of $3 \mathrm{~min}$ to obtain stable values. Calibration was done according to Salonen (1981) with $\mathrm{NaHCO}_{3}$ solution and yielded a linear correlation between displayed 
and real values in the range of measured $\mathrm{CO}_{2}$ concentrations $(r=0.999)$. The relative precision of the applied method is 1 to $4 \%$ of the measured values $(\mathrm{n}=5)$.

$\mathrm{O}_{2}$ profiles and flux calculations. Oxygen concentration profiles were measured with microelectrodes (Revsbech \& Ward 1983) just before the end of the tracer incubation period. The signals of the oxygen sensors were read on a picoamperemeter with built-in polarization voltage and a strip chart. The measuring circuit had a $90 \%$ response time of $1 \mathrm{~s}$. A 2-point calibration performed before and after every 3 to 5 profiles according to Revsbech \& Ward (1983) showed no detectable drift in the $\mathrm{O}_{2}$ sensor signal. The detection limit for oxygen was $0.3 \mu \mathrm{M}$.

The position of the sediment surface was determined accurately to $\pm 250 \mu \mathrm{m}$ by producing small disturbances in the stagnant water column. These led to a small $(3 \%)$ signal increase, 'stirring effect', when the water is freely advected to the sensor tip. Within the sediment there is no such effect (Gundersen \& Jørgensen 1990).

Diffusive fluxes for both $\mathrm{CO}_{2}$ and $\mathrm{O}_{2}$ were calculated according to Fick's First Law with the steepest gradients observed close to the sediment-water interface. We obtained temperature-corrected diffusion coefficients, $D_{0}$, using the Stokes-Einstein relation for $\mathrm{HCO}_{3}{ }^{-}\left(14^{\circ} \mathrm{C}: D_{0}=0.90 \times 10^{-5} \mathrm{~cm} \mathrm{~s}^{-1} ;\right.$ Li \& Gregory 1974). $\mathrm{HCO}_{3}^{-}$was considered as the predominant diffusing species, since $\mathrm{pH}$ was above 7.4 within the top $5 \mathrm{~cm}$ of all cores. Temperature-corrected diffusion coefficients for $\mathrm{O}_{2}$ were interpolated from data by Broecker \& Peng $\left(1974 ; 14^{\circ} \mathrm{C}: D_{0}=1.74 \times 10^{-5} \mathrm{~cm} \mathrm{~s}^{-1}\right)$. We derived the sediment diffusion coefficient, $D_{\mathrm{s}}$, according to the following equation for sandy sediments (Berner 1980, Dicke 1986):

$$
D_{\mathrm{s}}=\theta^{2} D_{0}=\phi D_{0}
$$

with $\theta^{2}$ (tortuosity) substituted by porosity, $\phi$, calculated from water content measurements to be 0.6 .

Diffusive flux, $J$, and increased flux due to bioturbation, effective flux, were calculated according to

$$
J=-K_{\text {BIO int. }} \phi D_{\mathrm{s}} \mathrm{d} C / \mathrm{d} z
$$

where $\mathrm{d} C / \mathrm{d} z$ is the concentration gradient at the sediment-water interface. In the case of molecular diffusive flux, $K_{\mathrm{BIO}}$ int $=1$. When enhanced, effective flux is observed, $K_{\mathrm{BIO}}$ int. $>1$.

\section{RESULTS}

A reduction of oxygen concentration to $20 \%$ affected the solute tracer transport (Fig. 2a to c). Bromide concentrations were higher at all depths in the sediment during most of the hypoxic and reoxygenation stages compared to the oxic stage. By modelling $\mathrm{Br}^{-}$propagation into the sediment, profiles of $D_{\text {eff }}$ were obtained that show several common features in all 3 stages. $D_{\text {efi }}$ was not constant with depth and had different maxima. The highest $D_{\text {eff }}$ modelled was $150 \times 10^{-6} \mathrm{~cm}^{2} \mathrm{~s}^{-1}$ and corresponded to a $K_{\mathrm{BIO}}$ of $\sim 30$. $D_{\text {eff }}$ was often at a minimum ( $K_{\mathrm{BIO}}$ of 1 to 9 ) at the sediment-water interface, where it was close to the coefficient obtained from molecular diffusion tracer experiments in previously frozen cores, $4.55 \pm 0.70 \times 10^{-6} \mathrm{~cm}^{2} \mathrm{~s}^{-1}(\mathrm{n}=9)$.

The average $K_{\mathrm{BIO}}$ within the top $10 \mathrm{~cm}$ sediment relative to molecular diffusion was largest in the hypoxic stage. It was 2 to 3 times greater than during the oxic stage (Table 1). The increase in $K_{\mathrm{BIO}}$ int. at the interface during the hypoxic relative to the oxic stage (Fig. 1b) indicated an increased exchange of pore water at the sediment surface. Standard deviations given in Table 1 also showed considerably larger core-to-core differences in $K_{\mathrm{BIO}}$ int. during the hypoxic stage (SD $= \pm 12$, range from 2 to 23$)$ than in the other stages $(\mathrm{SD}= \pm 2$, range from 2 to 5). These are not depicted in Fig. 2, which only shows results from 1 sediment core in which $\mathrm{O}_{2}, \mathrm{CO}_{2}$, and tracer were measured.

Macrofauna were present in all 12 sediment cores. Callianassa subterranea (18 ind. $\mathrm{m}^{-2}$ ) and Lanice conchilega $\left(28\right.$ ind. $\mathrm{m}^{-2}$ ) were most common. Echinocardium cordatum, Nephtys spp., and Amphiura filiformis
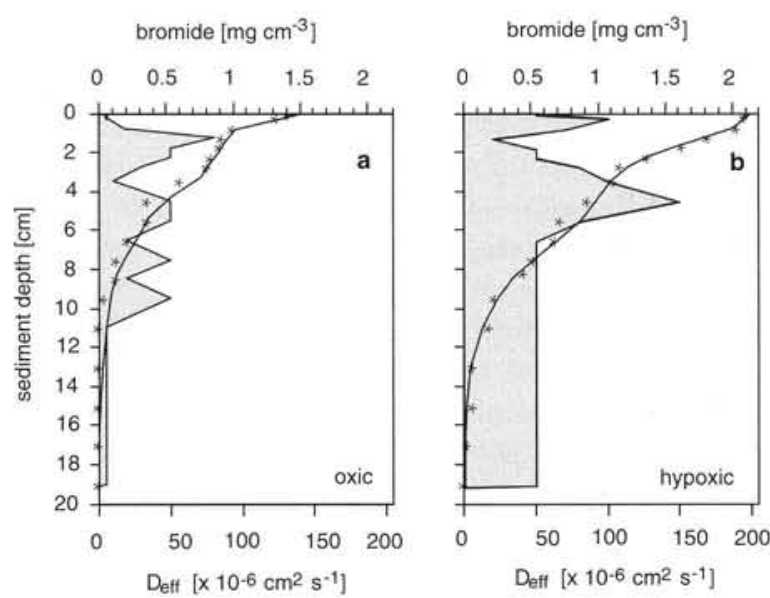

Fig. 2. Examples of bromide tracer distribution (*) in the sediment at the end of oxic hypoxic and reoxygenation stages during the oxygen depletion experiment. The shaded area shows the profile of the effective exchange coefficient $\left(D_{\text {eff }}\right)$ used to generate the $\mathrm{Br}^{-}$profile (solid line). The program changed $D_{\text {eft }}$ in order to achieve a close fit to the observed $\mathrm{Br}^{-}$concentrations. Data from 1 of 3 (hypoxic and reoxygenation stages) or 5 (oxic stage) parallel sediment cores are shown 
Table 1. Results derived from bromide tracer experiments characterizing enhanced solute transport. $\mathrm{n}$ : number of $20 \mathrm{~cm}$ diameter sediment cores; depth: penetration of the tracer ions; $K_{\mathrm{BIO}}$ int: coefficient of excess flux $( \pm 1$ SD) from the overlying water into the first model sediment layer $(0$ to $0.5 \mathrm{~cm}$ ) (SD indicates variability between cores); $K_{\mathrm{BIO}}$ : coefficient $( \pm 1 \mathrm{SD}$ ) within the top $10 \mathrm{~cm}$ of sediment

\begin{tabular}{|lccccc|}
\hline Stage & $\mathrm{n}$ & $\begin{array}{c}\text { Depth } \\
(\mathrm{cm})\end{array}$ & $K_{\mathrm{BIO} \text { int. }}$ & $K_{\mathrm{BIO}}$ & $\begin{array}{c}\text { Depth of maximum } \\
K_{\mathrm{BIO}}(\mathrm{cm})\end{array}$ \\
\hline Oxic & 5 & 10.0 & $1.2 \pm 0$ & $8 \pm 3$ & 3.9 \\
Hypoxic & 3 & 13.7 & $9.3 \pm 12$ & $22 \pm 6$ & 5.2 \\
Reoxygenated & 3 & 10.6 & $3.6 \pm 2$ & $15 \pm 9$ & 7.3 \\
\hline
\end{tabular}

after $4 \mathrm{~d}$ of reoxygenation (Fig. 3). Gradients within the first $0.5 \mathrm{~cm}$, however, showed little difference in the oxic and hypoxic stages leading to a calculated flux of 287 and $330 \mu \mathrm{mol} \mathrm{CO}_{2} \mathrm{~m}^{-2} \mathrm{~h}^{-1}$, respectively, considering $\mathrm{HCO}_{3}^{-}$the dominant species (Table 2). Diffusive $\Sigma \mathrm{CO}_{2}$ flux changed little during the experiment. Effective $\mathrm{\Sigma CO}_{2}$ flux reflected the changes in $K_{\mathrm{BIO}}$ int. in accordance with the minute changes in gradient slope. occurred in 5 sediment cores; 2 or 3 Ophiura albida were present in each core coresponding to a density of 90 ind. $\mathrm{m}^{-2}$ at the silty sand station (Salzwedel et al. 1985). Macrofauna numbers occurred evenly throughout the cores and cannot account for the extreme values of $K_{\mathrm{BIO} \text { int. }}$ or $K_{\mathrm{BIO}}$.

\section{$\mathrm{CO}_{2}$}

Dissolved $\mathrm{\Sigma CO}_{2}$ profiles (Fig. 3) changed during the course of the experiment. The total amount of $\mathrm{CO}_{2}$ increased: oxic < reoxygenated < hypoxic. Whereas in August 1989 profiles typically showed no clear gradient below $1 \mathrm{~cm}$ depth (Powilleit 1991), during hypoxic incubation a $\mathrm{\Sigma CO}_{2}$ maximum at $3 \mathrm{~cm}$ developed. From this maximum, a steep gradient upwards and downwards into the sediment emerged. The maximum concentration at that same depth could still be observed

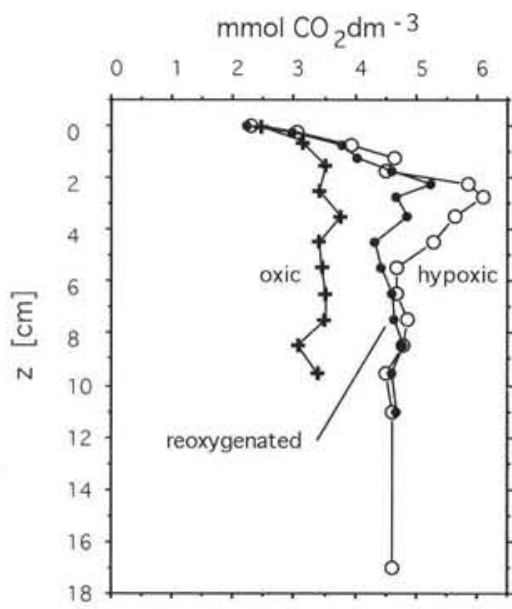

Fig. 3. Dissolved $\Sigma \mathrm{CO}_{2}$ profiles measured in the pore water of $20 \mathrm{~cm}$ diameter sediment cores. Sampling in August 1989 on board (oxic stage), and after Day 20 (hypoxic stage) and Day 26 (reoxygenation stage). Data from hypoxic and reoxygenation stages are from the same cores as $\mathrm{Br}^{-}$tracer profiles and $\mathrm{O}_{2}$ microprofiles

\section{$\mathrm{O}_{2}$}

Oxygen microprofiles (Fig. 4) showed the steepest gradients and relatively deep penetration of $\mathrm{O}_{2}$ in the oxic stage. In the hypoxic stage, oxygen concentration at the interface was reduced to roughly $10 \%$ saturation. Reoxygenation led to an intermediate gradient with oxygen penetration depth slightly exceeding that at the oxic stage. Molecular diffusive $\mathrm{O}_{2}$ flux (Table 2) under hypoxic conditions is roughly $1 / 10$ of the oxic stage flux. After $4 \mathrm{~d}$ of reoxygenation $\mathrm{O}_{2}$ flux only reached $60 \%$ of that at the oxic stage. In contrast to this, effec-

Table 2. Flux calculations at different stages of the experiment. Gradients of $\mathrm{CO}_{2}$ and $\mathrm{O}_{2}$ correspond to the profiles in Figs. $3 \& 4$. $D_{\mathrm{s}}$ : sediment diffusion coefficients at $14^{\circ} \mathrm{C}$ for hypoxic and reoxygenation stages ( ${ }^{\circ}$ due to different temperatures in the incubations, $D_{\mathrm{s}}$ was different in the oxic stage). Gradients, coefficients and flux values in the oxic stage are from measurements in June $\left(\mathrm{O}_{2}, 9^{\circ} \mathrm{C}\right)$ and August $1989\left(\mathrm{CO}_{2}\right.$, $16^{\circ} \mathrm{C}$ ). Each data set consisting of concentration gradient, $K_{\mathrm{BIO}}$ int, and water content for 1 flux estimate was determined from the same sediment core. Fluxes are calculated both for molecular diffusion and the increase due to bioturbation (effective flux: molecular flux $\times K_{\mathrm{BIO}}$ int.), and the molar ratio of fluxes $\left(\mathrm{CO}_{2} / \mathrm{O}_{2}\right)$ is given. See text for details

\begin{tabular}{|c|c|c|c|}
\hline & Oxic & Hypoxic & Reoxygenated \\
\hline \multicolumn{4}{|c|}{ Gradient $\left(\mu \mathrm{mol} \mathrm{cm}{ }^{-4}\right)$} \\
\hline $\mathrm{O}_{2}$ & 1.0 & 0.08 & 0.51 \\
\hline $\mathrm{CO}_{2}$ & 1.4 & 1.7 & 1.7 \\
\hline \multicolumn{4}{|l|}{$D_{\mathrm{s}}\left(\times 10^{-5} \mathrm{~cm}^{2} \mathrm{~s}^{-1}\right)$} \\
\hline $\mathrm{O}_{2}$ & $0.84^{*}$ & 1.01 & 1.01 \\
\hline $\mathrm{HCO}_{3}^{-}$ & $0.57^{*}$ & 0.54 & 0.54 \\
\hline$K_{\mathrm{BlO} \text { int. }}$ & 1.2 & 9.3 & 3.6 \\
\hline \multicolumn{4}{|c|}{$\mathrm{O}_{2}$ flux $\left(\mu \mathrm{mol} \mathrm{m}{ }^{-2} \mathrm{~h}^{-1}\right)$} \\
\hline Molecular & 302 & 29 & 185 \\
\hline Effective & 363 & 271 & 668 \\
\hline \multicolumn{4}{|c|}{$\mathrm{CO}_{2}$ flux $\left(\mu \mathrm{mol} \mathrm{m}^{-2} \mathrm{~h}^{-1}\right)$} \\
\hline Molecular & 287 & 330 & 330 \\
\hline Effective & 345 & 3073 & 1188 \\
\hline $\begin{array}{l}\text { Ratio of molecula } \\
\text { fluxes }\left(\mathrm{CO}_{2} / \mathrm{O}_{2}\right)\end{array}$ & 1.0 & 11.4 & 1.8 \\
\hline
\end{tabular}




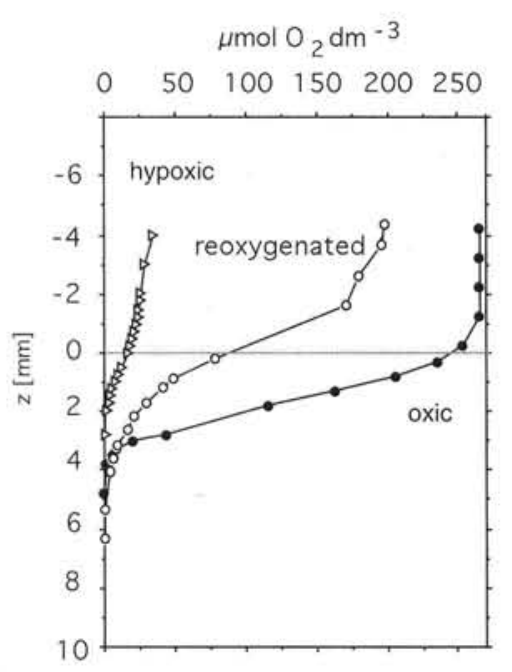

Fig. 4. $\mathrm{O}_{2}$ profiles measured after different incubations. Hypoxic and reoxygenation stage profiles from $20 \mathrm{~cm}$ cores. For comparison an $\mathrm{O}_{2}$ profile measured on board in June 1989 is shown for the oxic stage

tive $\mathrm{O}_{2}$ flux during the hypoxic stage remained similar to that during the oxic stage and increased during reoxygenation (Table 2 ).

The ratio of $\mathrm{CO}_{2}$ flux and $\mathrm{O}_{2}$ flux (Table 2) indicated the shift towards anaerobic metabolism during the hypoxic stage (Hargrave \& Phillips 1981). This ratio was $\sim 1$ during the oxic stage and reached 11 if interface fluxes during the hypoxic stage are considered. In the reoxygenation stage a $\mathrm{CO}_{2} / \mathrm{O}_{2}$ ratio of 1.8 was reached, demonstrating that at the end of the experiment normal conditions were not completely reestablished.

\section{DISCUSSION}

\section{Solute exchange}

Our experimental setup exposed the sediment cores to changing conditions of oxygen supply. In these transient conditions, a characteristic pattern emerged at the community level: transport changed to increased solute exchange between the sediment and the overlying water.

During the course of the experiment solute transport $\left(K_{\mathrm{BIO}}\right)$ tripled (from 8 to 22 ), then started to decrease during reoxygenation. Effective exchange coefficients at the sediment-water interface increased by a factor of 8 (Table 1). Such an effect had been observed by Rutgers van der Loeff et al. (1984) in an asphyxiation experiment. Average transport coefficients 8 times higher thi molecular diffusion coefficients are in agreement with data from the literature (Rutgers van der Loeff et al. 1984, Balzer et al. 1987). However, a 30fold increase in $D_{\text {eff }}$ to $1.5 \times 10^{-4} \mathrm{~cm}^{2} \mathrm{~s}^{-1}$ is among the highest values reported. The average penetration depth of bromide (Table 1) increased from 10 to $14 \mathrm{~cm}$ during the hypoxic stage.

The local character of solute transport due to advective fluid transport by bioirrigation was demonstrated by Aller (1982). In the present experiments, horizontal input of bromide tracer also occurred locally, along the burrows of the macrofauna, and increased the concentration in the adjacent sediment horizons. In our 1-dimensional model of this process, the changing slope in the measured tracer concentration curve as well as changes of $D_{\text {eff }}$ with sediment depth are evidence for such irrigation (Fig. 2a).

The experimental change during the hypoxic stage increased the maximum depth to which bromide is transported as well as the total amount of tracer in the sediment. This increased tracer flux may be due to changing concentration gradients along the interface across which tracer diffuses (burrow walls and sediment-water interface). It may also be due to newly constructed burrow wall surfaces as a result of flight reactions.

Irrigation of burrows by Callianassa subterranea is intermittent, not a continuous process, and flushes only parts of the burrow system. Burrow water tracer concentrations increased to near overlying water concentrations only in the uppermost $7 \mathrm{~cm}$ of the burrow system (Kitlar 1991). In a burrow which is only partially flushed, increased irrigation will transport oxic water deeper into the burrow system. Oxygen measurements in the burrow lumen of C. subterranea and Lanice conchilega indicated that the concentration in these areas is permanently at a transient state below overlying water concentrations (Forster 1991). In this case increased ventilation compensating for the low $\mathrm{O}_{2}$ content of the overlying water would result in steeper solute gradients. With increased ventilation there could also be additional burrow wall interface, previously not reached by bromide tracer or oxygen, across which solute could diffuse. This would enhance net $\mathrm{Br}^{-}$ flux without any new burrow construction.

At least 2 species present, Nephtys hombergii and Callianassa subterranea, are known to regulate oxic metabolic activity to levels of 30 to $40 \%$ oxygen saturation (Feldsgaard-Pedersen 1991, Powilleit 1991). This means they function as 'regulators' in the sense of Mangum (1973), compensating for low oxygen concentrations by increasing the transport supply. C. subterranea is known to be relatively tolerant to low oxygen conditions (Zebe 1982, Witbaard \& Duineveld 1989). Kept at $15 \%$ oxygen saturation it is able to sustain $90 \%$ of the aerobic metabolic rate for several days (Powilleit 1991). Under oxic conditions this species intermittently rests at $8 \mathrm{~cm}$ sediment depth, generating a respiratory 
current by irrigating its burrow with overlying water. It may be assumed that the hypoxic stage resulted in a higher frequency of irrigation. This explains the increased bromide concentration at 2 to $7 \mathrm{~cm}$ sediment depth (Fig. 2b).

There was only 1 observation of macrofauna fleeing from sediment conditions under hypoxia. Two individuals of the sea urchin Echinocardium cordatum reached the sediment surface during the course of the experiment. This does not produce new burrow surfaces to be irrigated but increases the transport at the sediment-water interface. E. cordatum has previously been reported the first to flee from sediments that fall anoxic. Detlefsen \& Westernhagen (1983), for example, observed mass mortality of E. cordatum at $30 \%$ oxygen saturation in the southern North Sea in 1981 to 1983.

We conclude that increased net tracer flux is due to irrigation rather than burrowing, even though some new burrow construction cannot be ruled out.

The observed increase in $K_{\mathrm{BIO}}$ int. during hypoxia is likely linked to the change in position within the sediment of Echinocardium cordatum already described above and to the activity of the brittlestars Ophiura albida and Amphiura filiforr. . Rosenberg et al. (1991) observed the ophiurid A. filiformis to move upwards from its oxic position below the sediment surface. It did so in order to reach oxygen or escape from hydrogen sulfide, and remained on the sediment surface extending its arms into the water above. The surface-dwelling $O$. albida even stood up on its arms to achieve better oxygenation of its gills (Baden et al. 1990). Even though we had no possibility to closely observe these 2 species in the present experiment, density of $O$. albida in the sediment cores analysed here was high (2 to 3 ind. per $100 \mathrm{~cm}^{2}$ ) and A. filiformis was present in smaller numbers. The intense movement of their arms may be responsible for the high surface $D_{\text {eff }}$ values in Fig. 2b.

\section{Changes in transport rates and pathways during hypoxia}

The effect of increased solute transport and mechanisms behind it clearly continued at the end of the experiment. This and considerable core-to-core differences (Table 1) limit general interpretation. Further discussion, therefore, focuses on measured gradients and calculated fluxes.

It has been demonstrated with a 3-dimensional burrow irrigation model (Aller 1980, 1982) that the shape of a concentration profile alone is not indicative of a particular reaction rate or burrow distribution. In the present study the concentration of dissolved $\Sigma \mathrm{CO}_{2}$ rose at 2 to $4 \mathrm{~cm}$ depth with increasing anoxia in the sedi- ment. Clearly the possibility exists for major changes in the microbial zonation and presumably fermentation and sulfate reduction increased at the expense of oxic respiration. However, we have no independent measurement of the rate of $\mathrm{CO}_{2}$ production and therefore will not discuss sources and reasons for potential changes in these rates. Instead we will discuss the possibility of a concentration increase with constant $\mathrm{CO}_{2}$ production rate and constant burrow distribution.

An increasing effective diffusive transport coefficent makes it seem unlikely that a sub-surface maximum in dissolved $\Sigma \mathrm{CO}_{2}$ could persist unless exceedingly high production rates were hypothesized. Why would any dissolved pore water species build up in the interstices and not diffuse out of the sediment?

Advective water flow, irrigation, by endobenthic fauna occurs locally, close to burrows and tubes. It does affect the adjacent sediment by molecular diffusion. However, in the case of a reactive chemical species this transport does not reach far into the sediment and does not produce a homogeneous concentration within horizontal sediment layers. This has been demonstrated for the tracer ion bromide (Kitlar 1991) that shows highest concentrations along burrows to produce average concentrations within a given sediment layer. In his 3-dimensional irrigation model Aller (1983) demonstrated how local input by irrigation alters average concentration of dissolved species.

It thus seems possible to distinguish between 'slow' and 'fast' pathways in the sediment with regard to transport. Within the interstices, molecular diffusion is the principal mechanism and transport is, therefore, relatively slow. In our experiment $\mathrm{CO}_{2}$ produced during hypoxia within the interstices was confined by limited exchange with the surrounding sediment compartments. Transport within the interstices was slow and, therefore, limiting to the rate of export of $\mathrm{CO}_{2}$ from the bulk sediment. Along burrows, irrigation faciliates relatively fast transport. It is only after this advection that transport into the bulk sediment occurs as a slow diffusive process. In this experiment, oxygen flux into the sediment took place to a large extent along burrows. This transport was fast, and therefore diffusive $\mathrm{O}_{2}$ flux at the sediment-water interface was of minor importance. Under oxic conditions, investigation of 2 prominent macrofaunal species in the same sediment found that $60 \%$ of $\mathrm{O}_{2}$ flux did not pass the sediment-water interface proper (Forster 1991), but entered the sediment through irrigation processes. Therefore a build-up of a $\mathrm{CO}_{2}$ maximum can be explained simply by considering a shift of solute tracer transport away from diffusion within the bulk sediment interstices to the advective transport pathways along burrows. In this scenario, macrofaunal pumping bypasses the sediment-water interface at large, de- 
creasing the importance of oxygen flux at the sediment surface proper in relation to total sediment oxygen uptake. Thus, we observed a pronounced shift in both the location and the type of transport induced by oxygen depletion.

Minimum (molecular diffusive) and maximum (effective) fluxes showed different patterns during the course of the experiment (Table 2). Effective flux calculations contain errors due to the modeling process (1-dimensional assumption of random walk process). Details specific to the dissolved chemical species in question, like adsorbtion and metabolic sinks, were not considered. On the other hand, diffusive flux figures obviously do not include important advective portions of the true fluxes, namely irrigational effects.

The magnitude of fluxes, both molecular and effective, during the oxic stage was similar. The molar ratio of the fluxes thus was close to 1 . In our calculations this is related to the use of the interface $K_{\mathrm{BIO}} \quad(=1.2)$ for effective flux calculations. During the hypoxic and reoxygenation stages much higher effective $\mathrm{CO}_{2}$ release was calculated. Following the above argument on transport pathways, we believe that tracer-derived transport coefficients are not related to the $\mathrm{CO}_{2}$ release rates from the bulk sediment interstices as much as to the $\mathrm{O}_{2}$ uptake rates via burrows. If so, the molecular dissolved $\mathrm{CO}_{2}$ flux $\left(330 \mu \mathrm{mol} \mathrm{CO} \mathrm{CO}_{2} \mathrm{~m}^{-2}\right)$ would have to be compared to the effective oxygen flux (271 $\mu \mathrm{mol}$ $\mathrm{O}_{2} \mathrm{~m}^{-2} \mathrm{~h}^{-1}$ ). This would lead to a molar $\mathrm{CO}_{2} / \mathrm{O}_{2}$ flux ratio of 1.2. Slightly elevated ratios have been found in several investigations (e.g. Hargrave \& Phillips 1981) and are generally attributed to the shift from oxic to anoxic metabolism. The present results indicate the role of transport by macrofaunal irrigation in this transient situation. The diffusive flux of oxygen calculated from the microgradient at the sediment surface obviously results in a low uptake $\left(29 \mu \mathrm{mol} \mathrm{O}_{2}\right.$ $\mathrm{m}^{-2} \mathrm{~h}^{-1}$ ). The corresponding diffusive molar $\mathrm{CO}_{2} / \mathrm{O}_{2}$ flux ratio is high (11.4) due to the insignificant diffusive oxygen flux number used in the calculation.

High effective $\mathrm{O}_{2}$ flux during reoxygenation may be due to the reoxidation of anaerobic end products in the sediment $\left(\mathrm{H}_{2} \mathrm{~S}, \mathrm{NH}_{4}{ }^{+}\right)$at the onset of reoxygenation.

Apparently, calculations of the molar flux ratio of $\mathrm{CO}_{2} / \mathrm{O}_{2}$ from sediment incubations can yield very different values (1 to 11 in our experiment) depending on the method used. The unreasonably high value of 11 calculated using diffusive $\mathrm{O}_{2}$ fluxes demonstrates the difficulty of calculating fluxes relevant for the total sediment community under these transient conditions.

On the community level the transport pattern changed to increased solute exchange between sediment and overlying water. Using terms of Mangum (1973) the community response was similar to that of a regulator, not a conformer. This is presumably because the majority of animals tried to sustain their oxygen supply by increased ventilation under hypoxia. Their metabolic energy was invested in compensatory pumping (e.g. Nephtys hombergii) or flight reactions (e.g. Echinocardium cordatum).

Diffusive oxygen flux is close to the oxic level after reoxygenation for $4 \mathrm{~d}$. The length of the community's reaction and its end remain unknown because the experiment was terminated early.

Acknowledgements. We thank Wolfgang Queisser and Michael Teucher for their help with the time-consuming control of the experiment. W. Koeve supplied the model to calculate solute transport. We also are indebted to S. Gerlach, P. Jensen, and 2 anonymous reviewers for valuable suggestions to earlier versions of the manuscript. This work was part of a Ph.D. thesis by S.F. supported by grant 03 F0548 of the German Federal Ministry of Research and Technology (BMFT).

\section{LITERATURE CITED}

Aller, R. C. (1980). Quantifying solute distributions in the bioturbated zone of marine sediments by defining an average microenvironment. Geochem. Cosmochim. Acta 44: 1955-1965

Aller, R. C. (1982). The effects of macrobenthos on chemical properties of marine sediment and overlying water. In: McCall, P. L., Tevesz, M. J. S. (eds.) Animal-sediment relations. Plenum Press, New York, p. 53-104

Aller, R. C., Aller, J. Y. (1992). Meiofauna and solute transport in marine muds. Limnol. Oceanogr. 37: 1018-1033

Altenbach, A. V. (1987). The measurement of organic carbon in foraminifera. J. foram. Res. 17: 106-109

Anderson, L. G., Hall, P. O. J., Iverfeldt, A., Rutgers van der Loeff, M. M., Sundby, B., Westerlund, S. F. G. (1986). Benthic respiration measured by total carbonate production. Limnol. Oceanogr. 31: 319-329

Baden, S. P., Pihl, L., Rosenberg, R. (1990). Effects of oxygen depletion on the ecology, blood physiology, and fishery of the Norwegian lobster Nephrops norvegicus. Mar. Ecol. Prog. Ser. 67: 141-155

Balzer, W., Erlenkeuser, H., Hartman, M., Müller, P. J., Pollehne, F. (1987). Diagenesis and exchange processes at the benthic boundary. In: Ruhmor, J., Walger, E., Zeitschel, B. (eds.) Seawater-sediment interactions in coastal waters - an interdisciplinary approach. Springer, Berlin, p. 111-161

Barnett, P. R. O., Watson, J., Connelly, D. (1984). A multiple corer for taking virtually undisturbed samples from shelf, bathyal and abyssal sediments. Oceanol. Acta 7(4): 399-408

Berner, R. A. (1980). Early diagenesis. A theoretical approach. Princeton University Press, Princeton, NJ

Broecker, W. S., Peng, T.-H. (1974). Gas exchange rates between air and sea. Tellus 26: 21-35

Dethlefsen, V., Westernhagen, H. v. (1983). Oxygen deficiency and effects on bottom fauna in the eastern German Bight. Meeresforsch. 30: 42-53

Dicke, M. (1986). Vertikale Austauschkoeffizienten und Porenwasserfluß an der Sediment/Wasser-Grenzfläche. Ph.D. dissertation, C. A. Universität, Kiel 
Dries, R.-R. (1975). Der Einfluß der Sauerstoffspannung auf die Stoffwechselgröße einiger Makrobenthosarten der westlichen Ostsee und des Kattegat. Kieler Meeresforsch. 1: $49-57$

Feldsgaard-Petersen, T. (1991). Metabolic adaptations to hypoxia of two species of polychaetes, Nephtys ciliata and Nephtys hombergii. J. comp. Physiol. B 161: 213- 215

Forster, S. (1991). Die Bedeutung biogener Strukturen für den Sauerstofffluß ins Sediment. Ph.D. dissertation, C. A. Universität, Kiel

Gaston, G. R. (1985). Effects of hypoxia on macrobenthos on the inner shelf off Cameron, Louisiana. Estuar. coast. Shelf Sci. 20: 603-613

Gundersen, J., Jørgensen, B. B. (1990). Microstructure of diffusive boundary layers and the oxygen uptake of the sea floor. Nature 345: 604-607

Hargrave, B. T., Phillips, G. A. (1981). Annual in situ carbon dioxide and oxygen flux across a subtidal marine sediment. Estuar. coast. Shelf Sci. 12: 725-737

Harper, D. E. J., McKinney, L. A., Salzer, R. R., Case, R. J. (1981). The occurrence of hypoxic bottom water off the upper Texas coast and its effects on the benthic biota. Mar. Sci. 24: $53-79$

Hendelberg, M., Jensen, P. (1993). Vertical distribution of the nematode fauna in a coastal sediment influenced by seasonal hypoxia in the bottom water. Ophelia 37: 83-94

Hickel, W., Bauerfein, Niermann, E. U., Westernhagen, H. v. (1989). Oxygen deficiency in the south-eastern North Sea: sources and biological effects. Ber. Biol. Anst. Helgoland 4: $1-148$

Kitlar, J. (1991). Der Einfluß der Bioturbation auf den Transport gelöster Stoffe im Porenwasser. Ph.D. dissertation, C. A. Universität, Kiel

Kremling, K, (1983). Determination of the major constituents. In: Grasshoff, K., Ehrhard, M., Kremling, K. (eds.) Methods of seawater analysis. Verlag Chemie, Weinheim, p. 249

Li, Y.-H., Gregory, S. (1974). Diffusion of ions in sea water and in deep-sea sediments. Geochim. Cosmochim. Acta 38: 703-714

Mangum, C. (1973). Responses of aquatic invertebrates to

This article was presented by T. Fenchel (Senior Editorial Advisor), Helsingør, Denmark declining oxygen conditions. Am. Zool. 13: 529-541

Pamatmat, M. (1978). Oxygen uptake and heat production in a biotic conformer (Littorina irotata) and a metabolic regulator (Uca pugnax). Mar. Biol. 48: 317-325

Powilleit, M. (1991). $\mathrm{CO}_{2}$-Messungen zur Untersuchung des anaeroben Stoffwechsels benthischer Evertebraten und zur Aktivitätsbestimmung der gesamten SedimentLebensgemeinschaft. Ph.D. dissertation, C. A. Universität, Kiel

Revsbech, N. P., Ward, D. M. (1983). Oxygen microelectrode that is insensitive to medium chemical composition: use in acid microbial mat dominated by Cyanidium caldarium. Appl. environ. Microbiol. 45 (3): $755-759$

Rosenberg, R., Hellmann, B., Johansson, B. (1991). Hypoxic tolerance of marine benthic fauna. Mar. Ecol. Prog. Ser. 79: $127-131$

Rutgers van der Loeff, M. M., Anderson, L. G., Hall, P. O. J., Iverfeldt, A., Josefson, A. B., Sundby, B., Westerlund, S. F. G. (1984). The asphyxation technique: an approach to distinguishing between molecular diffusion and biologically mediated water transport at the sediment-water interface. Limnol. Oceanogr. 29: 675-686

Salonen, K. (1981). Rapid and precise determination of total inorganic carbon and some gases in aqueous solutions. Water Res. 15: 403-406

Salzwedel, H., Rachor, E., Gerdes, D. (1985). Benthic macrofauna communities in the German Bight. Veröff. Inst. Meeresforsch. Bremerh. 20: 199-267

Schöttler, U., Grieshaber, M. (1988). Adaptation of the polychaete worm Scoloplos armiger to hypoxic conditions. Mar. Biol. 99: 215-222

Theede, H., Ponat, A., Schlieper, C. (1969). Studies on the resistance of marine bottom invertebrates to oxygen-deficiency and hydroden sulfide. Mar. Biol. 2: 325-337

Witbaard, R., Duineveld, G. C. A. (1989). Some aspects of the biology and ecology of the burrowing shrimp Callianassa subterranea (Montagu) (Thalassinidea) from the southern North Sea. Sarsia 74: 209-219

Zebe, E. (1982). Anaerobic metabolism in Upogebia pugettensis and Callianassa californiensis (Crustacea, Thalassinidea). Comp. Biochem. Physiol. 72 B: 613-617

Manuscript first received: January 17, 1994

Revised version accepted: September 21, 1994 